\title{
SELF EFFICACY PASIEN DIABETES MELLITUS TIPE 2 DI WILAYAH KERJA BPJS CABANG KEDIRI
}

\section{SELF EFFICACY PATIENTS DM TYPE 2 IN BPJS KEDIRI BRANCH AREA}

\author{
Christianto Nugroho* \\ Stikes Pamenang \\ * Korespondensi Penulis: christiantonug@gmail.com
}

\begin{abstract}
Abstrak
Diabetes mellitus (DM) merupakan sekelompok penyakit metabolik dengan karakteristik peningkatan kadar glukosa darah, Penderita DM seringkali mengalami kesulitan untuk menerima diagnose DM, terutama ketika ia mengetahui bahwa hidupnya diatur oleh diet makanan dan obatobatan. Pasien DM yang bersikap negatif terhadap pengobatan akan mengakibatkan kegagalan penatalaksanaan DM, hal ini dapat mempengaruhi kualitas hidup dan kemampuan sosial pasien, Pasien Diabetes mellitus (DM) cenderung mengalami gangguan mekanisme koping salah satunya adalah self efficacy. Tujuan penelitian ini adalah mengetahui self efficacy pada pasien DM tipe 2. Desain penelitian ini menggunakan deskripsi dengan sampel pada penelitian ini adalah pasien DM Type 2 yang tergabung dalam peserta Pronalis (Program Pengelolaan Penyakit Kronis) di wilayah kerja BPJS cabang Kediri di kelompok prolanis larasati dan prosehat bugar , Jawa Timur, Indonesia pada bulan April-Mei 2015. Sampel penelitian ini adalah semua peserta Prolanis berjumlah 34 orang yang dipilih secara total sampling. Data dikumpulkan menggunakan kuesioner DMSES (Diabetes Management Self Efficacy Scale), kemudian dianalisa menggunakan analisis diskripsi. Hasil penelitian ini menunjukkan Self Efficacy pada pasien DM tipe 2 dalam kateori sedang, ini mengindikasikan pasien DM belum mampu mengontrol penyakitnya secara maksimal yaitu dalam pengontrolan makan dan diet, program latihan/olah raga, dan pengobatan. Kesimpulan: Self Efficacy pada pasien DM tipe 2 dalam kategori sedang.
\end{abstract}

Kata kunci: Self Efficacy, DM tipe 2

\begin{abstract}
Diabetes mellitus (DM) is a group of metabolic diseases characterized by an increase in blood glucose levels. DM sufferers often have difficulty accepting a diagnosis of DM, especially when he knows that his life is governed by a diet of food and medicine. DM patients who are negative towards treatment will result in failure of DM management, this can affect the quality of life and social ability of patients, Diabetes mellitus (DM) patients tend to experience coping mechanism disorders, one of which is self efficacy. The purpose of this study was to determine self-efficacy in type 2 DM patients. The design of this study used the description of the sample in this study were DM Type 2 patients who were members of the Pronalis (Chronic Disease Management Program) in the working area of the Kediri BPJS branch in the Prolanis larasati group and prosehat fit, East Java, Indonesia in April-May 2015. The sample of this study were all 34 participants selected from total sampling. Data were collected using the DMSES (Diabetes Management Self Efficacy Scale) questionnaire, then analyzed using descriptive analysis. The results of this study indicate Self Efficacy in patients with type 2 DM in the medium category, this indicates that DM patients have not been able to control their disease to the fullest, namely in controlling food and diet, exercise I sports programs, and medication. Conclusion: Self Efficacy in patients with type 2 DM in the medium category.
\end{abstract}

Keywords: Self Efficacy, DM type 2

\section{Pendahuluan}

Diabetes mellitus (DM) merupakan sekelompok penyakit metabolik dengan karakteristik peningkatan kadar glukosa darah (hiperglikemia)Error! Reference source not found.00. Penderita DM seringkali 
mengalami kesulitan untuk menerima diagnose DM, terutama ketika ia mengetahui bahwa hidupnya diatur oleh diet makanan dan obat- obatan0. Pasien DM akan bersikap negatif apabila terjadi penolakan selama menjalani pengobatan, sikap negatif terhadap penyakit dan pengobatan akan mengakibatkan kegagalan penatalaksanaan DM, hal ini dapat mempengaruhi kualitas hidup dan kemampuan sosial pasien00.

Indonesia diperkirakan pada tahun 2030 akan memiliki penyandang DM sebanyak 21,3 juta jiwa0. Pasien DM dikelompok ini ratarata sudah mendapatkan informasi dari tenaga kesehatan dan media, terlebih mereka sudah masuk dalam komunitas DM dengan setiap bulannya mereka mendapatkan informasi penyakitnya. DM tipe 2 merupakan DM yang banyak diderita masyarakat dan biasanya terjadi setelah usia 40 tahun, pada orang yang kelebihan berat badan karena faktor gaya hidup serta pola makan0. Penelitian Ovaskeinen memberikan kesimpulan bahwa DM tipe 2 disebabkan oleh obesitas, diet yang tidak sehat, kurang aktivitas fisik, urbanisasi dan industrialisasi diperoleh hasil bahwa Body Mass Index (BMI) berhubungan dengan self efficacy $\mathrm{p}<0,010$.

Penyakit DM tipe 2 mengalami berbagai gangguan mekanisme koping pada diri penderita seperti gangguan self efficacy0. Penelitian pada 266 sampel diperoleh hasil bahwa skor self efficacy pada penderita DM tipe 2 sebesar 13,9\% rendah (skor 18-62). Keadaan ini menunjukkan bahwa penderita DM tipe 2 memiliki self efficacy yang rendah0.

Penderita DM tipe 2 mengalami berbagai keterbatasan dalam pengelolaan emosi, keyakinan kemampuan diri, gangguan pengaturan makan dan diet, gangguan aktivitas fisik, kontrol gula darah, pengobatan dan perawatan kaki0. Apabila hal ini tidak bisa dikontrol dengan baik, akan terjadi komplikasi. Komplikasi pada Diabetes Melitus dibagi menjadi dua yaitu komplikasi akut dan komplikasi kronis. Komplikasi akut meliputi ketoasidosis diabetik, hiperosmolar non ketotik, dan hipoglikemia, yang termasuk komplikasi kronik adalah makroangiopati, mikroangiopati dan neuropati0. Melihat banyaknya kasus DM dan komplikasi yang ada, maka perlu adanya penelitian sejauh mana self efficacy padapaien DM type 2.

\section{Metode}

Desain penelitian ini adalah deskriptif, 0 Sampel penelitian ini adalah semua peserta Prolanis (Program Pengelolaan Penyakit Kronis) di kelompok prolanis larasati dan prosehat bugar yang berada di wilayah kerja BPJS cabang Kediri berjumlah 34 orang yang dipilih secara total sampling0. Pengambilan sampel dilakukan dengan memberikan kuesioner kepada pasien berupa kuesioner DMSES (Diabetes Management Self Efficacy Scale), dengan kategori DMSES: Tinggi: $>140(>70 \%)$, Sedang :80-140 (40-70\%), Rendah: $<80(<40 \%) 00$, setelah data terkumpul dilakukan analisis diskripsi terhadap hasil self efficacy pasien tersebut.

\section{Hasil}

Self Efficacy penderita DM tipe 2

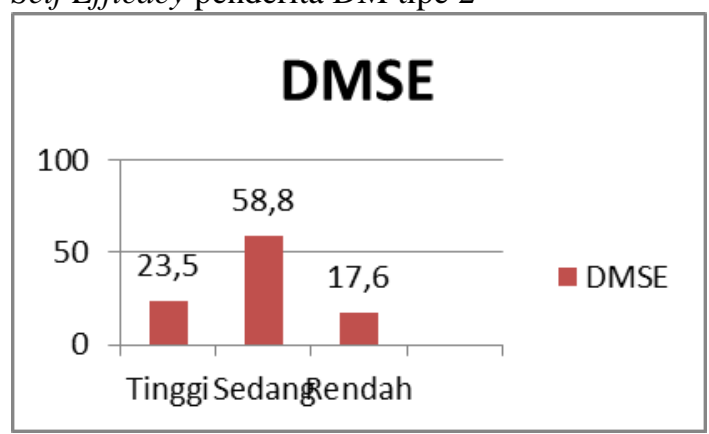

Diagram 1. Self Efficacy penderita DM tipe 2 di wilayah kerja BPJS cabang Kediri kelompok prolanis larasati dan prosehat bugar di kabupaten Kediri April-Mei 2015.

Hasil penelitian tentang sel efficacay pada pasien DM dengan DMSE mendapatkan rata-rata sedang di 58,8\%, dan yang memiliki self efficacy tinggi sebesar $23,5 \%$ dari jumlah responden.

\section{Pembahasan}

Hasil penelitian tentang sel efficacay pada pasien DM dengan DMSE mendapatkan rata-rata sedang di 58,8\%, dan yang memiliki self efficacy tinggi sebesar $23,5 \%$ dari jumlah responden.

Melihat hasil penelitian self efficacy pada pasien DM rerata yang terjadi adalah kategori sedang, dari proses wawancara terhadap pasien rata- rata menyebutkan bahwa belum mampu mengontrol penyakitnya secara maksimal yaitu dalam pengontrolan makan dan diet, program latihan/olah raga, dan pengobatan. 
Keyakinan diri pasien DM dalam pengelolaan makanan dan diet masih dalam kategori sedang, hal ini dapat terlihat bahwa responden belum mampu mengontrol makanan saat bepergian, mangenal makanan yang baik tetapi tidak mampu menjalankannya sesuai aturan diet. Salah satu manajemen diabetes mellitus yang baik adalah terpenuhi makanan sesuai dengan diet DM merupakan bagian kunci keberhasilan pengelolaan DM0.

Pengontrolan kadar gula darah,responden mengetahui cara memeriksakan kadar gula darahnya tetapi responden belum mampu mengenali saat kadar gula darah sedang naik atau turun. Pilar kelima yang dianjurkan kepada pasien DM monitoring level gula darah sendiri dapat mencegah dan mendeteksi kemungkinan terjadinya hipoglikemia dan hiperglikemia0.

Aktivitas fisik atau olah raga secara umum responden mengetahui pentingnya hal tersebut, tetapi dalam pelaksanaannya belum dilakukan dengan baik, olah raga yang dilakukan tidak secara teratur bahkan hanya 1 bulan $1 x$, ada yang menyatakan hanya saat pertemuan atau kegiatan prolanis ini dilakukan. Kegiatan aktivitas sehari-hari dan latihan jasmani secara teratur (3-4 kali/minggu selama kurang lebih 30 menit) merupakan salah satu pilar dalam pengelolaan DM, selain untuk menjaga kebugaran, latihan fisik dapat menurunkan berat badan dan memperbaiki sensivitas insulin, sehingga memperbaiki kendali kadar gula darah0.

Pengobatan dan kontrol rutin dilakukan oleh responden setiap bulan sekali melalui kegiatan prolanis ini, responden mampu memanfaatkan fasilitas yang diberikan pihak BPJS dengan baik. Intervensi farmakologi secara teratur dan mengiuti anjuran dokter memberikan pengontrolan gula darah secara baik0.

Peneliti sebelumnya menyatakan bahwa penderita DM tipe 2 memiliki self efficacy yang rendah0 dan mengalami keterbatasan dalam pengelolaan emosi, keyakinan kemampuan diri, gangguan pengaturan diet dan makan, gangguan aktivitas fisik, kontrol gula darah, pengobatan dan perawatan diri0. Semakin self efficacy rendah maka pengelolaan DM semakin rendah yang akan berakibat semakin banyak komplikasi yang terjadi pada individu tersebut dan sebaliknya.

\section{Kesimpulan}

Hasil penelitian tentang sel efficacay pada pasien DM dengan DMSE mendapatkan rata-rata sedang.

\section{Saran}

Dengan hasil penelitian diharapkan akan menjadi perhatian besar bagi unit pelayanan kesehatan dalam melakukan pengelolaan pasein DM, bukan hanya dari segi pengobatan saja tetapi juga memperhatikan dari self efficacy pasien masing masing.

\section{Ucapan Terima Kasih}

Terima kasih saya ucapkan kepada pihak BPJS cabang Kediri, kelompok prolanis larasati dan prosehat bugar dan semua pasien yang tergabung dalam kegiatan prolanis yang telah memberikan kesempatan untuk melakukan penelitian ini.

\section{Daftar Pustaka}

ADA. (2012). Diagnosis and Classification of Diabetes Melitus. Diabetes Care, II(1), 35.

Gustaviani, R. (2007). Buku Ajar Ilmu Penyakit Dalam (1 ed.). Jakarta: Universitas Indonesia.

Perkeni. (2011). Konsensus Pengendalian dan Pencegahan Diabetes Melitus Tipe2 di Indonesia 2011. jakarta: Perkeni.

Kai G.Kahl, U. C. (2014). Depression, anxiety disorder, and metabolic sydrome in a population at risk for type 2 Diabetes Melitus. Brain and Behaviour, 1-7.

Kariadi, S. H. (2009). Diabetes? Siapa Takut!!:Panduan lengkap untuk Diabetes, Keluarganya, dan Profesional Medis. Bandung: Qanita.

Soegondo, S. R. (2011). Konsensus pengelolaan dan pencegahan diabetes melitus tipe 2 di Indonesia 2011. Jakarta: PB Perkeni.

Depkes. (2013, september 08). DM penyebab kematian nomor 6 di dunia. Dipetik januari 14, 2015, dari Depkes: http://www.depkes.go.id/article/view/2383/di abetes-melitus-penyebab-kematian-nomor-6di-dunia-kemenkes-tawarkan-solusi-cerdikmelalui-posbindu.html

Tjokroprawiro, A. (2011). Hidup Sehat dan Bahagia Bersama Diabetes. Jakarta: PT Gramedia Pustaka Utama.

Marja Leena Ovaskainen, H. T. (2015). Perceived health-related self-efficacy associated with BMI in adults in a population-based survey. Journal of Public Health, 55-57.

Workman. (2006). Medical surgical nursing critical thinking for collaborative care. Ohia: Elseiver Sauders. 
Sandhi Wynn Nyut, N. H. (2010). self-efficacy, self-care behaviour and glycemic control among type- 2 diabetes patients attending two private clinic in yangon,myanmar. Southeas Asian J Trop Med Public Health, 943-951.

Notoatmodjo, S. (2012). Metodologi Penelitian Kesehatan. Jakarta: Rineka Cipta.

J. Van der Bijl, K. E. (2001). Strategies Enhancing Self - Efficacy in Diabetes Education. Scolary Iquary for Nursing Practice: An International Journal, 235-248.

Shi Q, O. S. (2010). Improving glycaemic control self-efficacy and glycaemic control behaviour in Chinese patients with type 2 diabetes mellitus: randomised controlled trial. Journal of Clinical Nursing, 398-404. 